\title{
Preparation of aromatic polyamidines and their transformation in polybenzimidazoles
}

\author{
B. Ch. Kholkhoev", V. F. Burdukovskii, D. M. Mognonov \\ Baikal Institute of Nature Management, Siberian Branch of the Russian Academy of Sciences, Sakhyanova Str. 6, 670047 \\ Ulan-Ude, Russia
}

Received 14 February 2014; accepted in revised form 28 April 2014

\begin{abstract}
Polymers with amidine groups $-\mathrm{NH}-\mathrm{C}(=\mathrm{NH})$ - in main chain were synthesized by two different approaches. The first strategy consists in polyaddition of dinitriles and diamines in acidic ionic liquids (ILs) which act as catalyst and solvent, while the second approach is based on polycondensation of 4,4'-oxybis(benzoic acid) diamide and diamines in Eaton's reagent (ER). The resulting polyamidines (PADs) with $M_{\mathrm{w}}$ up to $25000 \mathrm{~g} / \mathrm{mol}$ possess thermal stability on air up to $288^{\circ} \mathrm{C}$, and good solubility in polar organic solvents. Moreover dehydrocyclization of obtained PADs into polybenzimidazoles (PBIs) under the action of various oxidants was also studied in this work. The crosslinked films based on PBI and poly(amino imide) resin (PAIR) possess high mechanical characteristics. It has been proved that the crosslinked films based on PBI matrix are perspective materials for design the phosphoric acid electrolyte membranes for the medium temperature fuel cells.
\end{abstract}

Keywords: polymer synthesis, polymer blends, polyamidines, polybenzimidazoles, proton exchange membrane fuel cells

\section{Introduction}

In recent years, considerable researchers' attention has been focused on PADs owing to the wide prospects for their use in optoelectronics, organometallic catalysis, medicine, enzymology, and other fields [1-6]. Although polymers of this class show much promise, they have not been studied to a great extent. In terms of the position of amidine groups in the polymer chain, there are two groups of PADs (Figure 1), among which PADs-I have been most extensively studied [7-10]. PADs with structure II are much less studied compounds. Only a few examples of synthesis of these PADs are known [5, 6, 11-14]. Therefore development of synthetic routs to PADs-II is important problem. In addition to the fundamental importance of PADs-II, they can be used as precursors for the preparation of PBIs. Brand et al. [14] outlined possibility of preparing PBIs by oxida-

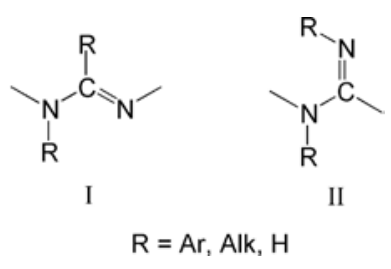

Figure 1. Structures of polyamidines

tive dehydrocyclization of PADs, which were synthesized by polyaddition of dinitriles with diamines in melt. However, the formed polymers had low molecular weights and were incapable to form films and press materials with satisfactory mechanical properties, and therefore they cannot be used in different areas of industry, in particular for proton exchange membrane fuel cells [15].

In this work successful modification of synthesis of aromatic PADs from dinitriles and diamines by using

\footnotetext{
*Corresponding author, e-mail: holh_bat@mail.ru

(C) BME-PT
} 
acidic ILs as catalyst and solvent is described. Moreover we developed a new method of synthesis of such polymers consisting in polycondensation of 4,4'-oxybis(benzoic acid) diamide and diamines using ER as condensing agent and solvent. The dependence of reaction conditions on molecular weights of the obtained PADs has been investigated in details. Synthesized polymers were characterized by Fourier transform infrared (FTIR) and nuclear magnetic resonance (NMR) spectroscopies, thermogravimetry (TGA) and gel permeation chromatography (GPC). Moreover dehydrocyclization of PADs into PBIs under the action of various oxidants was studied. Also, the mechanical properties and proton conductivity of membranes based on a blend of PBIs and PAIR were also determined.

\section{Experimental section}

\subsection{Materials}

1-butyl-3-methylimidazolium chloride ([BMIm] Cl) (99.4\%, 4900790100, Merck, Germany), 1-butyl-3methylimidazolium bromide ([BMIm]Br) $(99.8 \%$, 4900870100, Merck, Germany), 1-butyl-3-methylimidazolium tetrafluoroborate ([BMIm]BF4) $(99.9 \%$, 4900490100, Merck, Germany), 1-butyl-2,3dimethylimidazolium chloride ([BM2 Im] Cl) $(99.8 \%$, 4900210100, Merck, Germany), 1-Ethyl-3-methylimidazolium chloride ([EMIm]Cl) $(99.8 \%, 4900540100$, Merck, Germany), methanesulfonic acid (MSA) ( $\geq 99.5 \%, 471356$, Sigma-Aldrich, Germany), terephthalonitrile (99\%, 8210760250, Merck, Germany), isophthalonitrile $(99 \%, 8413550100$, Merck, Germany), all diamines ( $\geq 99 \%$, Sigma-Aldrich, Germany), aluminium chloride (99\%, 563919, SigmaAldrich, Germany), phosphorus pentoxide ( $\geq 98 \%$, 298220, Sigma-Aldrich, Germany), sodium hypochlorite solution (1056142500, Merck, Germany) were used without further purification.

Reagent-grade N,N-dimethylformamide (DMF), $\mathrm{N}, \mathrm{N}$-dimethylacetamide (DMAc), N-methyl-2pyrrolidone (MP), dimethylsulfoxide (DMSO), chloroform, dichloromethane, methanol were obtained from Sigma-Aldrich (Germany), and were purified by distillation over $\mathrm{P}_{2} \mathrm{O}_{5}$.

4,4'-oxybis(benzoic acid) diamide was synthesized by low-temperature condensation of 4,4'-oxybis (benzoic acid) dichloride with concentrated aqua ammonia solution as described previously [16]. 4,4'dicyanodiphenyloxide was obtained by dehydration of 4,4'-oxybis(benzoic acid) diamide using thionyl chloride in DMF solution [17].

Acidic $\mathrm{Al}_{\mathrm{x}} \mathrm{Hal}_{\mathrm{y}}{ }^{-}$containing ionic liquids were prepared by the slow addition of the desired amount of $\mathrm{AlHal}_{3}$ to the imidazolium salt. The reaction was left to stir overnight at $0^{\circ} \mathrm{C}$ for $24 \mathrm{~h}$, in order to allow a perfect homogenization of the resulting acidic ionic liquid [18].

For the preparation of Eaton's reagent (ER) following procedure was used. Phosphorus pentoxide and methanesulfonic acid were placed in a $50 \mathrm{~mL}$ roundbottom flask with a magnetic stirrer. The mixture was stirred at $60-70^{\circ} \mathrm{C}$ until there was complete dissolution of $\mathrm{P}_{2} \mathrm{O}_{5}$ [19]. This mixture was used as a solvent for polycondensation and was prepared just before use.

PAIR was supplied from 'Karbolit' plant (Kemerovo city, Russia) and was used as received.

\subsection{Polymer synthesis}

\subsubsection{Synthesis of polyamidines in ionic liquids}

PADs were synthesized in a $50 \mathrm{~mL}$ three-necked flask equipped with a stirrer and an inlet and an outlet for argon. The typical procedure is as follows. First, $0.12 \mathrm{~g}(0.9375 \mathrm{mmol})$ of terephthalonitrile and $0.1875 \mathrm{~g}(0.9375 \mathrm{mmol})$ of $4,4^{\prime}$-diaminodiphenyloxide were added to the clear liquid of [BMIm] $\mathrm{Al}_{2} \mathrm{Cl}_{7}$. Next, the reaction mixture was placed in a bath, and the temperature was raised up to $190-200^{\circ} \mathrm{C}$. After about $15-16 \mathrm{~h}$, viscous solution was poured into a $5 \%$ aqueous $\mathrm{KOH}$ solution. Finally, precipitate was filtrated, washed several times with water (typically three times) until neutral $\mathrm{pH}$ of the washing water, and dried in vacuo at $60^{\circ} \mathrm{C}$ for $24 \mathrm{~h}$. Anal. Calcd for $\mathrm{C}_{20} \mathrm{H}_{16} \mathrm{~N}_{4} \mathrm{O}: \mathrm{C}, 73.17 \% ; \mathrm{H}, 4.88 \%$; N, 17.07\%; O, 4.88\%. Found: C, 72.05\%; H, 4.72\%; N, 18.93\%. IR ( $\mathrm{KBr}$ pellet): $3450(\mathrm{~m}), 3000$ (m), $2750(\mathrm{~m}), 1605\left(\mathrm{~s}, v_{\mathrm{C}=\mathrm{N}}\right), 1568(\mathrm{w}), 1500(\mathrm{~s}), 1368$ $\left(\mathrm{w}, v_{\mathrm{C}-\mathrm{N}}\right), 1200\left(\mathrm{~s}, v_{\mathrm{C}-\mathrm{O}-\mathrm{C}}\right) \mathrm{cm}^{-1}$.

\subsubsection{Synthesis of polyamidines in Eaton's reagent}

Typical example of the polycondensation follows. First, 4,4'-oxybis(benzoic acid) diamide $0.768 \mathrm{~g}$ $(0.003 \mathrm{~mol}), \quad 4,4^{\prime}$-diaminodiphenyloxide $0.6 \mathrm{~g}$ $(0.003 \mathrm{~mol})$ were stirred in ER for $\sim 0.5 \mathrm{~h}$ at $100^{\circ} \mathrm{C}$ under argon. After the dissolution of the monomers, the temperature was raised up to $120^{\circ} \mathrm{C}$, and the mixture was stirred for $4-5 \mathrm{~h}$ at this temperature. 
The resulted extremely viscous solution was diluted with methanesulfonic acid. This polymer solution was poured into water, and neutralized with sodium carbonate solution. The polymer was collected by filtration, washed with hot water and dried in vacuo at $60^{\circ} \mathrm{C}$ for $24 \mathrm{~h}$. Anal. Calcd for $\mathrm{C}_{26} \mathrm{H}_{20} \mathrm{~N}_{4} \mathrm{O}_{2}$ : C, $74.29 \%$; H, 4.76\%; N, 13.33\%; O, 7.62\%. Found: C, $73.42 \%$; H, 4.84\%; N, $14.72 \%$. IR (KBr pellet): 3450 $(\mathrm{m}), 3010(\mathrm{~m}), 2830(\mathrm{~m}), 1620\left(\mathrm{~s}, v_{\mathrm{C}=\mathrm{N}}\right), 1540(\mathrm{w})$, $1500(\mathrm{~s}), 1350\left(\mathrm{w}, v_{\mathrm{C}-\mathrm{N}}\right), 1210\left(\mathrm{~s}, v_{\mathrm{C}-\mathrm{O}-\mathrm{C}}\right) \mathrm{cm}^{-1}$.

\subsubsection{Synthesis of polybenzimidazoles}

A suspension of $0.5 \mathrm{~g}$ of PAD $2 \mathrm{a}$ in $5 \mathrm{~mL}$ of $1 \mathrm{M}$ aqueous $\mathrm{HCl}$ and $7 \mathrm{~mL}$ of methanol was refluxed with stirring for $30 \mathrm{~min}$. After cooling the resulting solution to room temperature, $2 \mathrm{~mL}$ of a hydrogen peroxide solution $(40.8 \%, 35 \mathrm{mmol})$ was added dropwise. The mixture was stirred for an additional $20 \mathrm{~min}$. Then $15 \mathrm{~mL}$ of DMF was added to make the solution fully homogeneous. After adding $6 \mathrm{M}$ aqueous $\mathrm{KOH}(0.6 \mathrm{~mL})$, the mixture was heated at $100^{\circ} \mathrm{C}$ for $4 \mathrm{~h}$. Then the reaction solution was poured into $300 \mathrm{~mL}$ of ice-cold water. The obtained polymer was filtered off and dried in a vacuum oven at $50^{\circ} \mathrm{C}$ to constant weight. Anal. Calcd for $\mathrm{C}_{20} \mathrm{H}_{12} \mathrm{~N}_{4} \mathrm{O}$ : C, $74.08 \%$; H, 3.70\%; N, 17.28\%; O, 4.94\%. Found: C, $73.81 \%$; H, 3.87\%; N, 16.93\%. IR (KBr pellet): $3450(\mathrm{~m}), 3000(\mathrm{~m}), 2800(\mathrm{~m}), 1630$ (s, $\left.v_{\mathrm{C}=\mathrm{N}}\right), 1545(\mathrm{w}), 1450(\mathrm{~s}), 1360\left(\mathrm{w}, v_{\mathrm{C}-\mathrm{N}}\right), 1110(\mathrm{~s})$, $1200\left(\mathrm{~s}, v_{\mathrm{C}-\mathrm{O}-\mathrm{C}}\right), 730(\mathrm{~s}) \mathrm{cm}^{-1}$.

\subsection{Measurements}

Inherent viscosity [ $\eta$ ] (IV) was measured with an Ubbelohde-type viscometer at $20^{\circ} \mathrm{C}$ in DMF or in $\mathrm{H}_{2} \mathrm{SO}_{4}$. FTIR spectra were recorded on Excalibur FTS 4000 spectrometer (Germany) in the wave number range $4000-400 \mathrm{~cm}^{-1}$. The samples were prepared as $\mathrm{KBr}$ pellets. ${ }^{13} \mathrm{C}$ NMR spectra were recorded on a Varian VXR-500S spectrometer (USA) operating at $125 \mathrm{MHz}$. DMSO- $\mathrm{d}_{6}$ was used as both solvent and internal standard $\left(\delta\left({ }^{13} \mathrm{C}\right)=39.50 \mathrm{ppm}\right)$. Dynamic TGA was performed on STA 449 C14/G Jupiter (Netzsch, Germany) $5^{\circ} \mathrm{C} / \mathrm{min} . \mathrm{Al}_{2} \mathrm{O}_{3}$ was used as a reference. Gel permeation chromatography (GPC) was performed on 'Waters' chromatograph (USA) at $20^{\circ} \mathrm{C}$. Tetrahydrofuran was used as eluent (flow rate $-0.5 \mathrm{~mL} / \mathrm{min}$ ). Weight-average molecular weights $\left(M_{\mathrm{w}}\right)$ were calculated relative to polystyrene standards.
Film materials were prepared by casting a $10-15 \%$ polymer solution in DMF onto a glass support. PBIPAIR films of various compositions were prepared by mixing $10-15 \%$ solutions of the initial polymers in DMF. The solution distributed on the substrate surface was dried on air at first, and then a crude film was post-dried in vacuo at $40-70^{\circ} \mathrm{C}$ to remove remains of DMF. The films were kept in the extended state under a load of $0.5 \mathrm{kPa}$ in a vacuum oven at $160^{\circ} \mathrm{C}$ for $48 \mathrm{~h}$. Membranes were obtained by soaking cured films into water solutions of $\mathrm{H}_{3} \mathrm{PO}_{4}$ with concentrations of $9 \mathrm{M}$ for 5 days. After soaking, the membranes were removed from solutions of $\mathrm{H}_{3} \mathrm{PO}_{4}$, and acid residues were wiped with a filter paper. The membranes were dried in vacuo at room temperature up to a constant weight. Water content in obtained membranes does not exceed $8-10 \%$.

A proton conductivity of a membrane was measured by van der Pauw four-probe method [20] at current frequency of $500 \mathrm{~Hz}$ under dry argon flow and calculated according to Equation (1):

$$
\sigma=\frac{I_{12}}{4.53 \cdot h \cdot U_{34}}
$$

where $\sigma$ is a proton conductivity $[\mathrm{S} / \mathrm{cm}] ; I_{12}$ is a current between flank probes of 1 and $2[\mathrm{~A}] ; U_{34}$ is a voltage between flank probes of 3 and $4[\mathrm{~V}] ; h$ is a thickness of a sample $[\mathrm{cm}]$.

\section{Results and discussion}

\subsection{Preparation of polyamidines}

The proposed concept to aromatic PADs with an improved molecular weight focuses on two different approaches. The first strategy consists in polyaddition of dinitriles and diamines in ionic liquids, while the second one is based on polycondensation of diamide and diamines in Eaton's reagent.

\subsubsection{Polyamidines from dinitriles and diamines} It is known [21-23] that the reactions of aromatic nitriles with amines are well-catalyzed by protic and aprotic acids. Among many catalysts, the aprotic acids (Lewis acids) have been found to be very useful to provide good yields of desired amidines [21, 22], but in general, the yields are not high enough to consider their use in the formation of high molecular weight polymers. Along with this, acidic ILs on the basis of metal halides can be regarded as an alternative for the traditional heterogeneous and 
homogeneous catalysts, in particular aluminium chloride [24]. These ILs were successfully used for different acid-catalyzed reactions, such as Friedel-Crafts alkylation and acylation [24-27], nitrations [24, 25] and halogenations $[24,25,28]$.

These data altogether in combination with the ability of ILs to dissolve different organic compounds (in particular, nitriles and amines) and polymers served as the basis for the studying the possibility of synthesis of PADs from aromatic dinitriles and diamines in ionic media (Figure 2). Moreover, the efficacy of ILs in the synthesis of polyheteroarylenes was shown [29-32].

In order to determine the optimal conditions for the reaction, the polyaddition of terephthalonitrile and $4,4^{\prime}$-diaminodiphenyl oxide in $[\mathrm{BMIm}] \mathrm{Cl} / \mathrm{AlCl}_{3}$ was studied (synthesis of polymer 1a).

Molar ratio [BMIm] Cl/AlCl3 strongly influences on catalytic activity of IL in acid-catalyzed reactions [24]. Therefore, at first, the effect of amount of aluminium chloride in IL system on [ $\eta$ ] of the PAD was examined. It has been found that in the mixtures [BMIm] $\mathrm{Cl} / \mathrm{AlCl}_{3}$ containing $0 \div 1$ equivalents of $\mathrm{AlCl}_{3}$, which are, in fact, eutectic mixtures of [BMIm]Cl and [BMIm] $\mathrm{AlCl}_{4}$, only low-molecular weight PADs are formed $([\eta]=0.07-0.11 \mathrm{dL} / \mathrm{g})$. Molecular weight of the obtained PAD significantly increases when polymerization was carried out in the systems containing $>1$ equivalents of $\mathrm{AlCl}_{3}$ (Figure 3 ). The best results were achieved in IL containing 2 equivalents of $\mathrm{AlCl}_{3}$, i.e. under conditions where strongly acidic IL $[\mathrm{BMIm}] \mathrm{Al}_{2} \mathrm{Cl}_{7}$, generated

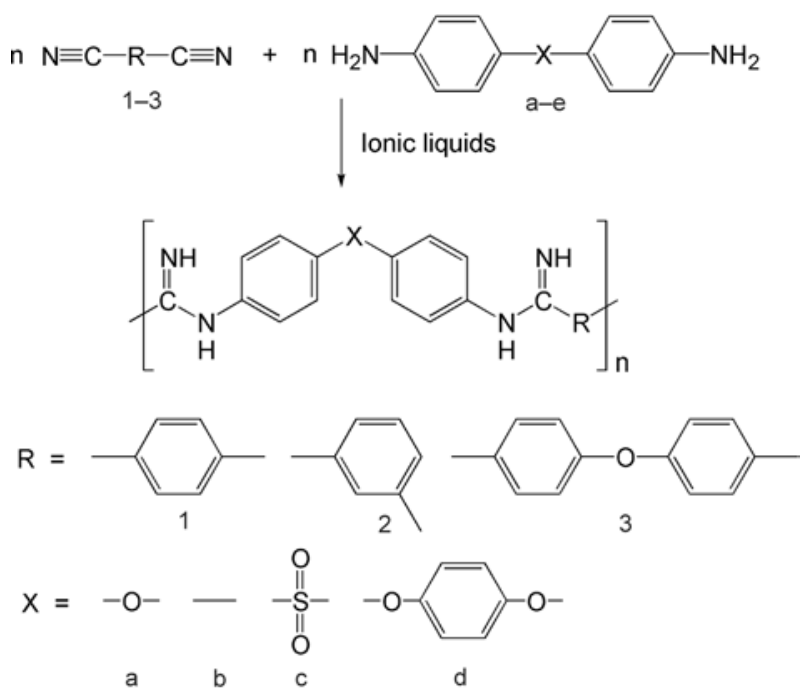

Figure 2. Synthesis of polyamidines from dinitriles and diamines

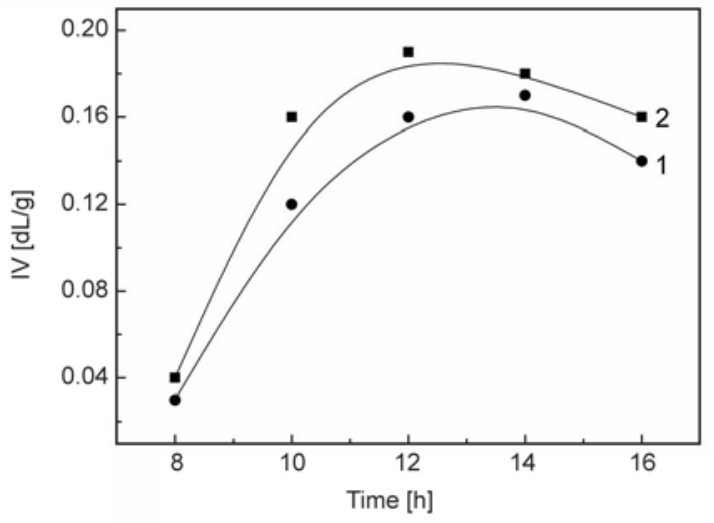

Figure 3. Effect of reaction time on IV of PAD 1a obtained by the polyaddition in IL: $[\mathrm{BMIm}] \mathrm{Cl} / \mathrm{AlCl}_{3}=$ $1: 1.1(1),[\mathrm{BMIm}] \mathrm{Cl} / \mathrm{AlCl}_{3}=1: 2(2)$, at $160^{\circ} \mathrm{C}$ and monomer concentration of $0.6 \mathrm{~mol} / \mathrm{L}$

from [BMIm] $\mathrm{AlCl}_{4}$ and $\mathrm{AlCl}_{3}$, serves as the reaction medium [24].

The IV of the synthesized polymer also depends on the temperature and concentration of the initial monomers. The temperature of $190-200^{\circ} \mathrm{C}$ and the concentration of monomers $1.0 \mathrm{~mol} / \mathrm{L}$ are optimal (Figure 4). Further increase in the temperature and the concentration of the monomers results in noticeable reduction of the $[\eta]$ of the PAD.

Under the optimal reaction conditions, the polymerization also occurs in other studied ILs (Table 1). The PAD with the highest molecular weight $([\eta])$ is formed in $[\mathrm{BMIm}] \mathrm{Al}_{2} \mathrm{Br}_{7}$ and $[\mathrm{BMIm}] \mathrm{Al}_{2} \mathrm{Cl}_{7}$, while the $[\eta]$ of PAD obtained in conventional organic solvents (nitrobenzene, sulfolane) and in melt does not exceed 0.13 and $0.28 \mathrm{dL} / \mathrm{g}$, respectively [33].

On the basis of these studies, then, the polyaddition of various dinitriles with diamines was carried out

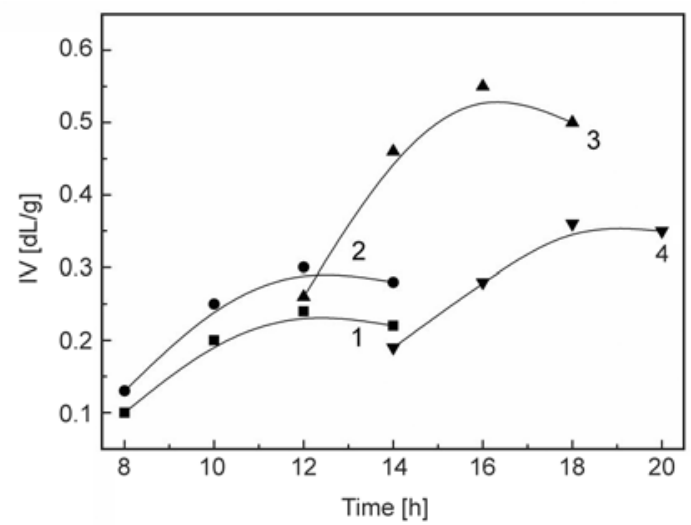

Figure 4. Effect of reaction time and monomer concentration on IV of PAD 1a obtained by the polyaddition in [BMIm] $\mathrm{Al}_{2} \mathrm{Cl}_{7}$, at $190-200^{\circ} \mathrm{C}$ and monomer concentration of $0.6(1), 0.8$ (2), 1.0 (3) and $1.2(4) \mathrm{mol} / \mathrm{L}$ 
Table 1. Effect of nature of ionic liquids on intrinsic viscosity of polyamidine 1a

\begin{tabular}{|c|c|c|c|c|c|}
\hline \multirow[t]{2}{*}{ № } & \multirow[t]{2}{*}{ IL } & & & & \multirow[t]{2}{*}{$\begin{array}{c}I^{\mathrm{a}} \\
{[\mathrm{dL} / \mathrm{g}]}\end{array}$} \\
\hline & & $\mathbf{R}_{1}$ & $\mathbf{R}_{2}$ & $\mathbf{Y}^{-}$ & \\
\hline 1 & [BMIm] Cl & $\mathrm{C}_{4} \mathrm{H}_{9}$ & $\mathrm{H}$ & $\mathrm{Cl}$ & 0.07 \\
\hline 2 & {$[\mathrm{BMIm}] \mathrm{Al}_{2} \mathrm{Cl}_{7}$} & $\mathrm{C}_{4} \mathrm{H}_{9}$ & $\mathrm{H}$ & $\mathrm{Al}_{2} \mathrm{Cl}_{7}$ & 0.55 \\
\hline 3 & {$[\mathrm{EMIm}] \mathrm{Al}_{2} \mathrm{Cl}_{7}$} & $\mathrm{C}_{2} \mathrm{H}_{5}$ & $\mathrm{H}$ & $\mathrm{Al}_{2} \mathrm{Cl}_{7}$ & 0.19 \\
\hline 4 & {$\left[\mathrm{BM}_{2} \mathrm{Im}\right] \mathrm{Al}_{2} \mathrm{Cl}_{7}$} & $\mathrm{C}_{4} \mathrm{H}_{9}$ & $\mathrm{CH}_{3}$ & $\mathrm{Al}_{2} \mathrm{Cl}_{7}$ & 0.30 \\
\hline 5 & {$[\mathrm{BMIm}] \mathrm{Al}_{2} \mathrm{Br}_{7}$} & $\mathrm{C}_{4} \mathrm{H}_{9}$ & $\mathrm{H}$ & $\mathrm{Al}_{2} \mathrm{Br}_{7}$ & 0.42 \\
\hline 6 & {$[\mathrm{BMIm}] \mathrm{BF}_{4}$} & $\mathrm{C}_{4} \mathrm{H}_{9}$ & $\mathrm{H}$ & $\mathrm{BF}_{4}$ & 0.23 \\
\hline
\end{tabular}

${ }^{a}$ Measured in sulfuric acid at $20^{\circ} \mathrm{C}$

under found optimal reaction conditions (Figure 2). The results are shown in the Table 2 . The polyaddition proceeded in homogeneous solution and gave quantitative yields of polymers with IV up to $0.55 \mathrm{dL} / \mathrm{g}$.

One of the advantages of ILs is the ability to use them in the recycle. Therefore it was interesting to reuse of $[\mathrm{BMIm}] \mathrm{Al}_{2} \mathrm{Cl}_{7}$ after polymerization of aromatic dinitriles and diamines. The recycle was performed as follows: first, reaction solution was poured into chloroform or dichloromethane; second, the obtained precipitate was collected by filtration; and finally, mixture of IL and organic solvent was separated by vacuum distillation. It was found that yield of regenerated IL was $60-70 \%$. The reason for the loss of IL could be due to strong complexation of IL

Table 2. Characteristics of polyamidines obtained from dinitriles and diamines in [BMIm] $\mathrm{Al}_{2} \mathrm{Cl}_{7}$

\begin{tabular}{|c|c|c|c|}
\hline No & PAD & $\begin{array}{r}\mathbf{I V}^{\mathbf{a}} \\
{[\mathbf{d L} / \mathbf{g}]}\end{array}$ & $\begin{array}{c}\text { Decomposition temperature }^{\mathbf{b}} \\
{\left[{ }^{\circ} \mathbf{C}\right]}\end{array}$ \\
\hline 1 & $1 \mathrm{a}$ & $0.55^{\mathrm{c}}$ & 275 \\
\hline 2 & $2 \mathrm{a}$ & 0.51 & 272 \\
\hline 3 & $3 \mathrm{a}$ & 0.32 & - \\
\hline 4 & $1 \mathrm{~b}$ & 0.52 & 288 \\
\hline 5 & $2 \mathrm{~b}$ & 0.44 & - \\
\hline 6 & $3 \mathrm{~b}$ & 0.27 & 282 \\
\hline 7 & $1 \mathrm{c}$ & 0.40 & - \\
\hline 8 & $2 \mathrm{c}$ & 0.33 & - \\
\hline 9 & $3 \mathrm{c}$ & 0.22 & - \\
\hline 10 & $1 \mathrm{~d}$ & 0.53 & - \\
\hline 11 & $2 \mathrm{~d}$ & 0.46 & - \\
\hline 12 & $3 \mathrm{~d}$ & 0.29 & \\
\hline
\end{tabular}

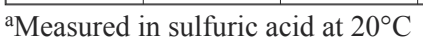

${ }^{\mathrm{b}}$ Temperature of $10 \%$ weight loss determined by TGA at a heating rate of $5^{\circ} \mathrm{C} / \mathrm{min}$

${ }^{\mathrm{c}} M_{\mathrm{w}}=19000 \mathrm{~g} / \mathrm{mol}, M_{\mathrm{w}} / M_{\mathrm{n}}=1.62(\mathrm{GPC})$. Film properties: tensile strength $(\sigma)=29.5 \mathrm{MPa}$, elongation $(\varepsilon)=4.2 \%$. with the formed PAD. Investigation of precipitate obtained after pouring of reaction mixture in chlorinated solvent confirmed this assumption. PAD/IL complexes can be easily hydrolyzed by dissolution in a mixture of $1 \mathrm{~N}$ aqua $\mathrm{HCl}$ and $\mathrm{CH}_{3} \mathrm{OH}(1 / 1, \mathrm{v} / \mathrm{v})$ and further precipitation of PAD with $5 \%$ aqua $\mathrm{KOH}$ solution.

So, we not only successfully synthesized aromatic PADs based on dinitriles and diamines in chloroaluminate ILs, but also regenerated ionic solvent.

\subsubsection{Polyamidines from $4,4^{\prime}$-oxybis(benzoic acid) diamide and diamines}

With consideration for the fact that diamides transform into dinitriles under the action of dehydrating agents, it was advisable to examine the synthesis of PADs through the 'direct polycondensation', which is based on the interaction of diamines and diamides in a condensing medium. Being one of the most effective agents for obtaining various polyheteroarylenes [34-36], Eaton's reagent $\left(\mathrm{CH}_{3} \mathrm{SO}_{3} \mathrm{H}_{2} \mathrm{P}_{2} \mathrm{O}_{5}=\right.$ $10: 1, \mathrm{wt} / \mathrm{wt}$ ) was selected as a condensing medium. Aromatic PADs were synthesized according to the Figure 5. The main features of polycondensation were investigated for the interaction of 4,4'-oxybis (benzoic acid) diamide and 4,4'-diaminodiphenyl oxide (synthesis of polymer 4a Figure 5).

The effect of the synthesis temperature on the molecular mass of the PAD was studied in the range of $100-140^{\circ} \mathrm{C}$, because the rate of reaction was very low at temperatures below $100^{\circ} \mathrm{C}$, whereas decomposition of the main component of Eaton's reagent, methanesulfonic acid, began at a temperature above $150^{\circ} \mathrm{C}$. Polycondensation performed at $120^{\circ} \mathrm{C}$ and a concentration of initial monomers of $0.6 \mathrm{~mol} / \mathrm{L}$ for 


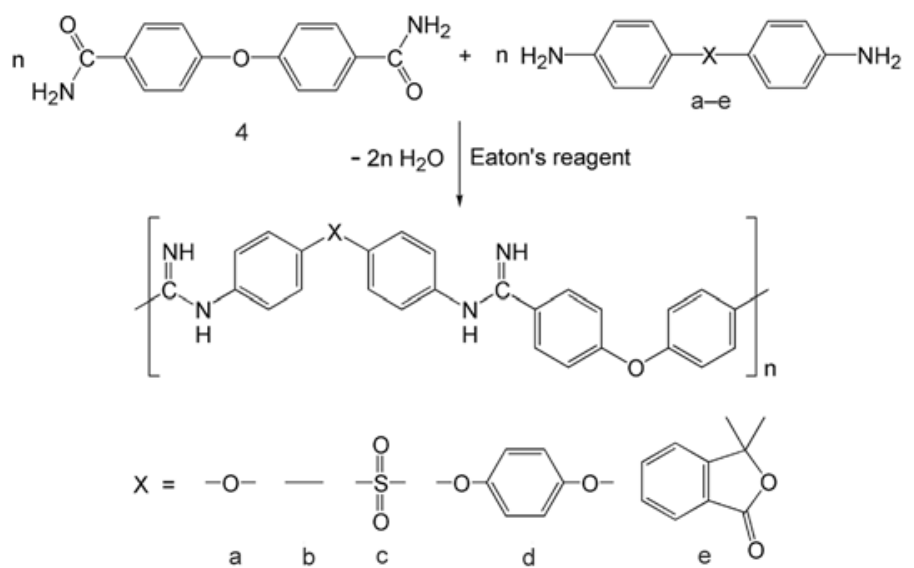

Figure 5. Synthesis of polyamidines from 4,4'-oxybis(benzoic acid) diamide and diamines

$10 \mathrm{~h}$ yielded the PAD with the highest $[\eta]$ value, $0.20 \mathrm{dL} / \mathrm{g}$. At a temperature of $100-120^{\circ} \mathrm{C}$, the polycondensation proceeded with the formation of a transparent light brown solution, whereas at $140^{\circ} \mathrm{C}$, after $6-8 \mathrm{~h}$, the reaction solution became dark brown probably owing to the degradation of monomers and/or polymer.

Further study of polycondensation showed that the molecular mass of the formed PAD is strongly affected by the concentration of the initial monomers. It was found that the highest molecular mass PAD is formed at a concentration of monomers of $0.8 \mathrm{~mol} / \mathrm{L}$; a further increase in concentration leads to a marked decline in the molecular mass of the PAD. The molar ratio of phosphorus pentoxide to diamide for a concentration of monomers of $0.8 \mathrm{~mol} / \mathrm{L}$ in Eaton's reagent $\left(\mathrm{CH}_{3} \mathrm{SO}_{3} \mathrm{H}: \mathrm{P}_{2} \mathrm{O}_{5}=10: 1\right.$, wt/wt $)$ was 1.32. Because the polymer prepared under these conditions had the highest $[\eta]$ value, it was advisable to investigate polycondensation at the found optimum ratio, but at higher both monomer concentrations and content of phosphorus pentoxide. As shown in reference [37], the use of additional amounts of $\mathrm{P}_{2} \mathrm{O}_{5}$ leads to a considerable increase in the molecular masses of the polymers.

Experiments demonstrated that the addition of $\mathrm{P}_{2} \mathrm{O}_{5}$ during polycondensation resulted in the formation of polymers showing limited solubility in conventional organic solvents, although this reaction occurred under homogeneous conditions. However, if additional amounts of the dehydrating agent were added at the reaction onset (immediately during preparation of the reaction solution) well soluble polymers were formed. It was shown (Figure 6) that the highest molecular mass products are formed at a monomer concentration of $1.0 \mathrm{~mol} / \mathrm{L}([\eta]=0.51 \mathrm{dL} / \mathrm{g})$.

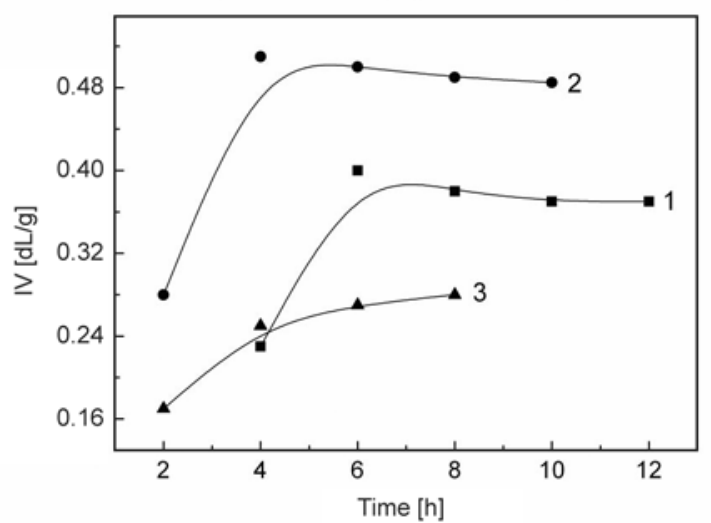

Figure 6. Effect of reaction time and monomer concentration on IV of PAD 4a obtained by the polycondensation in ER (mole ratio monomer $/ \mathrm{P}_{2} \mathrm{O}_{5}=$ $1 / 1.32)$, at $120^{\circ} \mathrm{C}$ and monomer concentrations of 0.8 (1), $1.0(2), 1.2(3) \mathrm{mol} / \mathrm{L}$

With allowance for the found optimum conditions $\left(T=120^{\circ} \mathrm{C}, t=4-5 \mathrm{~h}\right.$, a phosphorus pentoxide to monomer molar ratio of 1.32, and a monomer concentration of $1 \mathrm{~mol} / \mathrm{L}$ ), various PADs were synthesized via the above described Figure 5.

The polycondensation of 4,4'-oxybis(benzoic acid) diamide and a number of aromatic diamines occurred under homogeneous conditions and produced PADs with high yields and $[\eta]=0.23-0.65 \mathrm{dL} / \mathrm{g}$ (Table 3 ). However, in the case of diamides of iso- and terephthalic acids and diamines, only low-molecular-mass products were obtained. This fact makes it possible to assume that imino carbocations $-\mathrm{C}_{6} \mathrm{H}_{4}-\mathrm{C}^{+}=\mathrm{NH}$ serve as active intermediates in polycondensation. In fact, the best results were attained in the case of 4,4'-oxybis(benzoic acid) diamide, which forms an imino carbocation stabilized by an electron-donor ether group. In the case of diamides of iso- and terephthalic acids, the formation of imino carbocations is extremely difficult because of the presence of 
Table 3. Characteristics of polyamidines obtained from 4,4'-oxybis(benzoic acid) diamide and diamines in Eaton's regent

\begin{tabular}{|c|c|c|c|}
\hline № & PAD & $\begin{array}{c}\mathbf{I V}^{\mathbf{a}} \\
{[\mathbf{d L} / \mathbf{g}]}\end{array}$ & $\begin{array}{c}\text { Decomposition temperature } \\
{\left[{ }^{\mathbf{b}} \mathbf{C}\right]}\end{array}$ \\
\hline 1 & $4 \mathrm{a}$ & $0.51^{\mathrm{c}}$ & 268 \\
\hline 2 & $4 \mathrm{~b}$ & 0.48 & 280 \\
\hline 3 & $4 \mathrm{c}$ & 0.44 & 274 \\
\hline 4 & $4 \mathrm{~d}$ & $0.65^{\mathrm{d}}$ & 269 \\
\hline 5 & $4 \mathrm{e}$ & 0.23 & 246 \\
\hline
\end{tabular}

${ }^{a}$ Measured in DMF at $20^{\circ} \mathrm{C}$

${ }^{\text {b}}$ Temperature of $10 \%$ weight loss determined by TGA at a heating rate of $5^{\circ} \mathrm{C} / \mathrm{min}$

${ }^{\mathrm{c}} M_{\mathrm{w}}=20000 \mathrm{~g} / \mathrm{mol}, M_{\mathrm{w}} / M_{\mathrm{n}}=1.56(\mathrm{GPC})$

${ }^{\mathrm{d}} M_{\mathrm{w}}=25000 \mathrm{~g} / \mathrm{mol}, M_{\mathrm{w}} / M_{\mathrm{n}}=1.54(\mathrm{GPC})$. Film properties: tensile strength $(\sigma)=32.1 \mathrm{MPa}$, elongation $(\varepsilon)=3.5 \%$.

electron-acceptor groups. Similar relationships were observed in references [34-36] for the synthesis of polybenzazoles and poly(ether ketones) in Eaton's reagent.

Thus, high-molecular-mass PADs may be easily prepared via the direct polycondensation of 4,4'-oxybis (benzoic acid) diamide with various diamines in Eaton's reagent. This approach differs from conventional procedures by a high rate of polymer formation and mild reaction conditions.

\subsubsection{Characterization of polyamidines}

The structures of PADs were investigated by a combination of elemental analysis, IR investigation, and ${ }^{13} \mathrm{C}$ NMR spectroscopy. The chemical shift of the amidine carbon atom is observed in the ${ }^{13} \mathrm{C}$ NMR spectrum at $\approx 158 \mathrm{ppm}$. Typical NMR spectrum of PAD $4 \mathbf{b}$ is presented in Figure 7. Elemental analysis data are in a good agreement with the calculated values. The IR spectra of the polymers show characteristic absorption bands at $1608-1615(\mathrm{C}=\mathrm{N})$, 1360-1370 (C-N), and 3500-2500 (N-H, $\left.\mathrm{C}_{\mathrm{Ar}}-\mathrm{H}\right)$

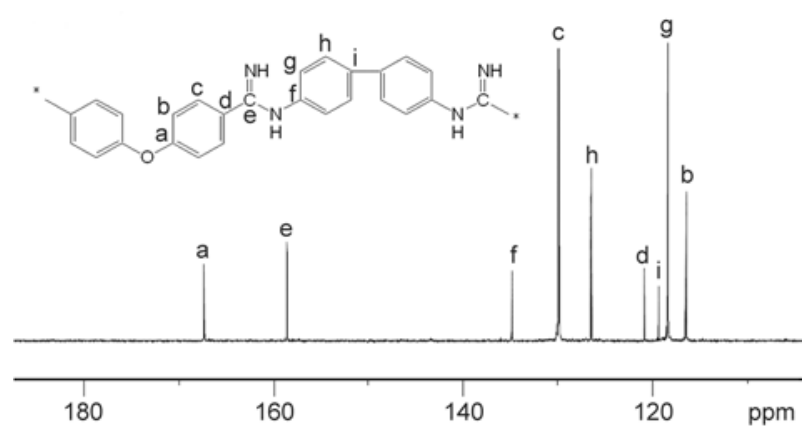

Figure 7. $\mathrm{NMR}{ }^{13} \mathrm{C}$ spectrum of PAD $4 \mathbf{b}$ $\mathrm{cm}^{-1}$, thereby indicating the formation of amidine functional groups [38].

The thermal properties of PADs were evaluated via TGA in the air and argon atmospheres and the data are summarized in Tables 2 and 3. All the samples used for studying the TGA were subjected to exhaustive drying in a vacuum oven at $60^{\circ} \mathrm{C}$. Typical TG curves of PADs $\mathbf{4 b}$ and $\mathbf{1 b}$ are shown in Figure 8. For all the samples two distinct different weight losses on TG curves on air are observed. We believe that oxidative dehydrocyclization of PAD in more thermally stable PBI under the action of oxygen occurs during TG experiment on air. In argon atmosphere one-step degradation of PADs is observed, which indirectly indicates the formation of benzimidazole rings during TGA in the presence of oxygen. These assumptions, however, need to be further examined with more effective characterization techniques. The $10 \%$ weight loss temperatures both in air and argon were at around $246-288^{\circ} \mathrm{C}$.

The polymers are fully soluble in concentrated sulfuric acid, concentrated formic acid and in polar organic solvents (DMF, DMAA, MP, THF, etc.) at room temperature or under slight heating. Moreover, all of the synthesized polymers are soluble in a mixture of $1 \mathrm{~N}$ aqua $\mathrm{HCl} /$ methanol $(1 / 1, \mathrm{v} / \mathrm{v})$. Solubility of polymers in conventional organic solvents allowed to determine their molecular masses by GPC. As noted in Tables 2 and 3 the PADs have moderate molecular masses $\left(M_{\mathrm{w}}\right)$ up to $25000 \mathrm{~g} / \mathrm{mol}$. Films prepared by casting of polymer solutions in DMF had tensile strength of 29.5-32.1 MPa and elongation of $3.5-4.2 \%$.

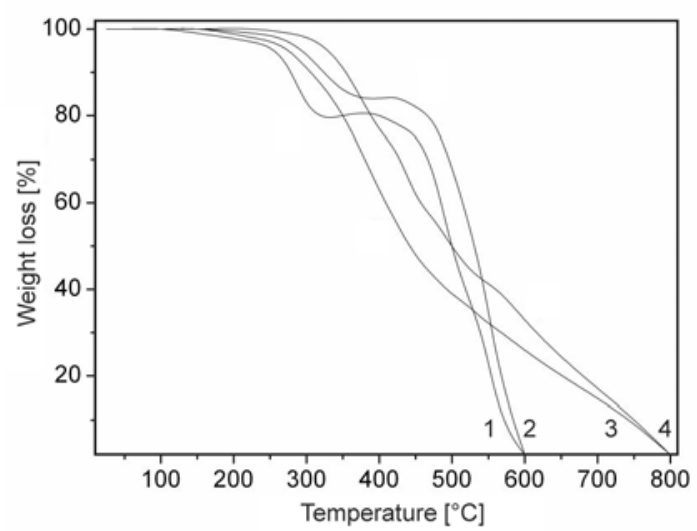

Figure 8. TG curves of PADs $\mathbf{4 b}(1,3)$ and $\mathbf{1 b}(2,4)$ in air and argon atmosphere, respectively 


\subsection{Preparation of polybenzimidazoles by oxidative dehydrocyclization of polyamidines}

Practical importance of synthesized PADs increases if they can be used as precursors for the preparation of high-performance PBIs. Therefore, it seemed appropriate to study oxidative dehydrocyclization of these PADs in detail (Figure 9) and to analyze the operation characteristics of PBI membranes prepared by this procedure.

The idea of preparing benzimidazole from $\mathrm{N}$-aryl substituted amidine hydrochloride (proposed by Grenda et. al. [39]) consist in generation from the azomethine bond in amidine hydrochloride of an uncharged electron-deficient species, nitrene, which, being extremely reactive, undergoes addition at the $o$-position of the benzene ring, thus closing the benzimidazole heterocycle.

In order to investigate the oxidative dehydrocyclization, transformation of PAD 2a was studied in detail. Also cyclization of PAD $\mathbf{4} \mathbf{d}$ was carried out under the optimal reaction conditions.

The transformation was performed in solution using hydrogen peroxide or sodium hypochlorite as oxidants. The PAD was converted to the soluble form using $1 \mathrm{M}$ aqueous $\mathrm{HCl}$ and methanol. After vigorous stirring with heating for $30 \mathrm{~min}$, the polymer dissolved virtually fully. Subsequent addition of the oxidant caused formation of a precipitate, which was dissolved by adding a small amount of DMF. To initiate the generation of nitrenes, we added to the reaction mixture $6 \mathrm{M}$ aqueous $\mathrm{KOH}$ and heated to $100^{\circ} \mathrm{C}$.

The course of oxidative dehydrocyclization was monitored by IR spectroscopy (Figure 10), namely, by changes in the intensities of the characteristic absorption bands of the $\mathrm{N}-\mathrm{H}\left(3400\right.$ and $\left.3050 \mathrm{~cm}^{-1}\right)$ and $\mathrm{C}-\mathrm{N}\left(1360-1365 \mathrm{~cm}^{-1}\right)$ groups. The other char-

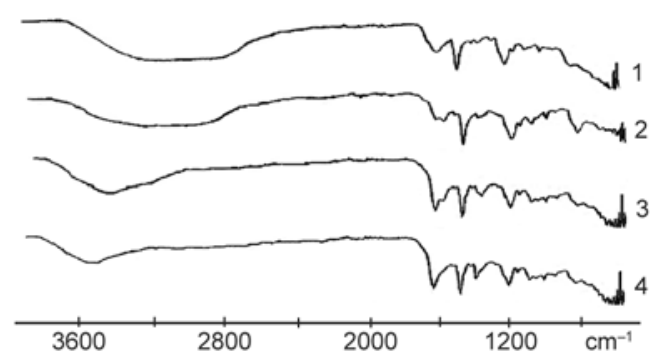

Figure 10. Evolution of the FTIR spectrum of PAD in the course of its transformation into PBI: PAD (1), intermediate states $(2,3)$, and PBI (4)

acteristic changes observed in the spectrum are shift of the $\mathrm{C}=\mathrm{N}$ absorption band at $1610 \mathrm{~cm}^{-1}(\Delta v=$ $20 \mathrm{~cm}^{-1}$ ), caused by transformation of the acyclic form into the cyclic form, and appearance of a new band at $730 \mathrm{~cm}^{-1}$, corresponding to 1,2-disubstituted benzene ring.

A study of the PAD transformation showed that the degree of conversion was not noticeably influenced by the polymer concentration in solution and by its molecular weight, whereas the oxidant content exerted appreciable influence. For example, when hydrogen peroxide was taken in an equimolar amount relative to PAD repeat unit, only $70 \%$ conversion was attained in $8 \mathrm{~h}$ (Figure 11, curve 4), after that the reaction became very slow. Threefold excess of the oxidant led to practically complete conversion in $6 \mathrm{~h}$ at $80^{\circ} \mathrm{C}$ (Figure 11, curve 2). It is interesting that the rates in both processes in the first hour were similar, but then the kinetics became different, apparently because of hindered diffusion in the polymer solution and limited accessibility of the amidine bond in the polymer chain to the oxidant molecules. With sodium hypochlorite used instead of hydrogen peroxide (Figure 11, curve 3), the cyclization rate slightly decreased. The maximal rate was attained with increasing temperature to $100^{\circ} \mathrm{C}$ : the cyclization was complete in $4 \mathrm{~h}$ (Figure 11, curve 1). Further increase

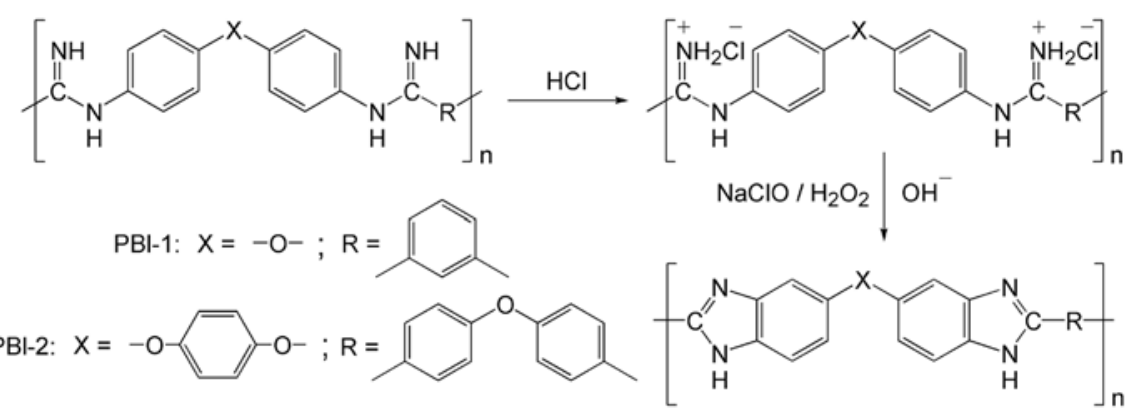

Figure 9. Oxidative dehydrocyclization of polyamidines in polybenzimidazoles 


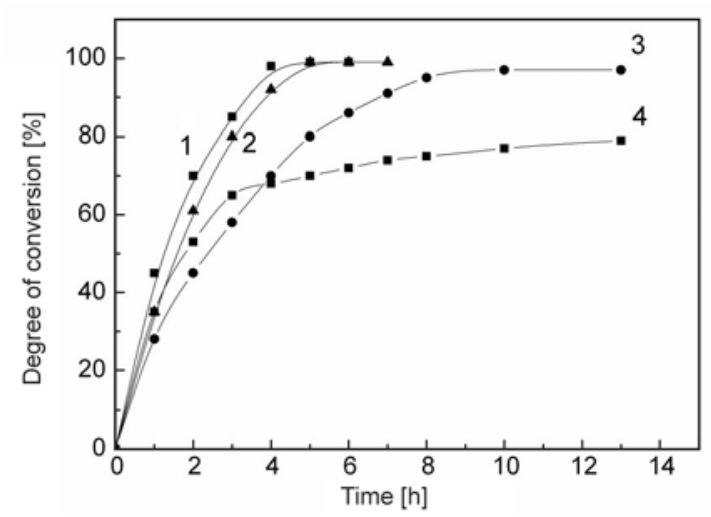

Figure 11. Degree of conversion $\gamma$ of PAD into PBI as a function of time $\tau$ : $[\mathrm{NaClO}] /[\mathrm{PAD}]=3,100^{\circ} \mathrm{C}(1)$; $\left[\mathrm{H}_{2} \mathrm{O}_{2}\right] /[\mathrm{PAD}]=3,80^{\circ} \mathrm{C}(2) ;[\mathrm{NaClO}] /[\mathrm{PAD}]=3$, $80^{\circ} \mathrm{C}(3)$ and $\left[\mathrm{H}_{2} \mathrm{O}_{2}\right] /[\mathrm{PAD}]=1,80^{\circ} \mathrm{C}(4)$

in temperature led to considerable deceleration of the reaction, probably because of decomposition of sodium hypochlorite.

The structure of thus obtained PBI-1 was confirmed by IR spectroscopy (Figure 10): characteristic absorption bands of 1,2-disubstituted benzene ring at $730 \mathrm{~cm}^{-1}$ and of $\mathrm{C}=\mathrm{N}\left(1630 \mathrm{~cm}^{-1}\right)$ and $\mathrm{C}-\mathrm{N}$ $\left(1360 \mathrm{~cm}^{-1}\right)$ bonds are observed. In the ${ }^{13} \mathrm{C}$ NMR spectrum of PBI-1, compared to those of the pristine PAD, new signals at $134.6 \mathrm{ppm}$ appear, confirming formation of the $o$-substituted aromatic ring; in addition, the signal of the amidine carbon atom at 158.6 ppm transforms into the signal of the benzimidazole carbon atom at $152.1 \mathrm{ppm}$.

According to TGA, the temperature of $10 \%$ weight loss on air for PBI- 1 is $490^{\circ} \mathrm{C}$ whereas for corresponding PAD this value is $275^{\circ} \mathrm{C}$. This fact also indirectly confirms the occurrence of cyclization.

PBI-2 was obtained similar to PBI-1 using sodium hypochlorite as oxidant at $100^{\circ} \mathrm{C}$.

The viscosity characteristics of PBIs suggest that the transformation of PADs is not accompanied by a change in their molecular weights.

Both obtained PBIs are fully soluble in concentrated sulfuric and formic acids and dissolve in amide solvents at slight heating. By casting 10-15\% solutions of PBIs in DMF onto glass supports, we obtained films with tensile strength of $68.0-71.6 \mathrm{MPa}$ and elongation of $2-3 \%$.

One of the most practically important properties of membranes based on PBI is ionic conductivity, allowing their use in fuel cells. However, doping the PBI-1 with orthophosphoric acid drastically decreased the strength of the membrane, making it practically unsuitable for use. For example, tensile strength of membrane decreased by $67.5 \%$, becoming as low as 23.27 MPa. Therefore, to improve the strength characteristics of film materials, we performed structuring of PBI with three-dimensional PAIR prepared from $\mathrm{N}, \mathrm{N}^{\prime}$-(4,4'-diphenylmethane) bis-maleimide and 4,4'-diaminodiphenylmethane. For this purpose, we mixed solutions of PBI and PAIR, prepared film materials, and heat-treated them at $230^{\circ} \mathrm{C}$ for $7 \mathrm{~h}$. Opening of the unsaturated bond of the terminal maleimide ring led to the formation of a 3D network in which PBI was retained owing to mechanical interweaving of macromolecular chains. It should be noted, however, that intermolecular interaction of the $\mathrm{C}=\mathrm{C}$ bonds of the resin with secondary amino groups of the benzimidazole ring of PBI, with the formation of a graft copolymer, can occur along with PAIR polymerization. Correspondingly, we observed in the IR spectra a low-frequency shift of the absorption band of the carbonyl groups, caused by formation of the less strained succinimide ring. Thus, we prepared film materials with satisfactory strength characteristics from the PBI-PAIR blends of various compositions (Figure 12).

As seen from the obtained data, addition of $10 \mathrm{wt} \%$ PAIR to PBI results in a sharp increase in the tensile strength. Further increase in the amount of the resin in a blend with both PBIs leads to a decrease in the film strength. Obviously, the 90:10 weight ratio of PBI and PAIR in the blend is optimal. The 90:10 PBI-1-PAIR membrane was doped with 9M orthophosphoric acid to constant weight. After that, the strength characteristics decreased by only $10-15 \%$, and the ionic conductivity of the membrane was $1.15 \cdot 10^{-3} \mathrm{~S} / \mathrm{cm}$. With an increase in temperature, the membrane conductivity also increased with the activation energy of $28 \pm 2 \mathrm{~kJ} / \mathrm{mol}$, reaching $3 \cdot 10^{-2} \mathrm{~S} / \mathrm{cm}$

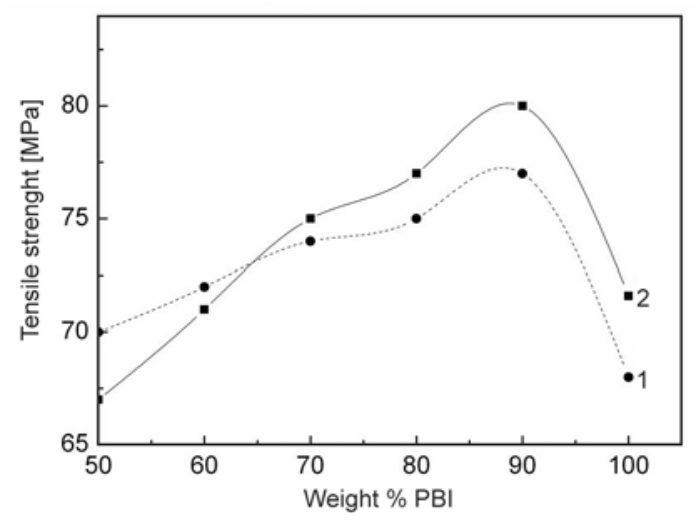

Figure 12. Tensile strength as a function of composition of PBI-PAIR blends. PBI-1 (1) and PBI-2 (2) 


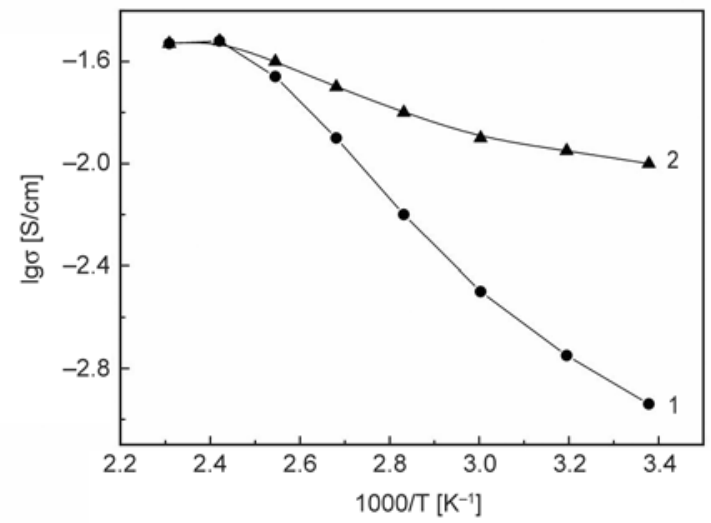

Figure 13. Temperature dependence of the ionic conductivity $\sigma$ of the 90:10 PBI-PAIR membrane doped with phosphoric acid (1) and of the same membrane additionally modified with acidic zirconium phosphate (2)

at $160^{\circ} \mathrm{C}$ (Figure 13, curve 1). These values are similar to the conductivity of conventional membranes based on PBIs. However mechanical properties of doped blend membrane of PBI and PAIR are considerably higher than those of common membranes on the base of PBIs [15].

It is interesting that additional treatment of the doped membrane with acidic zirconium phosphate leads to an increase in the conductivity at low temperatures by almost an order of magnitude $\left(1.0 \cdot 10^{-2} \mathrm{~S} / \mathrm{cm}\right.$ at $23^{\circ} \mathrm{C}$ ) and to a decrease in the activation energy to $8.5 \pm 0.5 \mathrm{~kJ} / \mathrm{mol}$. However, further increase in temperature leads to only a slight increase in the conductivity, and already at $120^{\circ} \mathrm{C}$ the conductivities of the doped membrane and membrane treated with zirconium phosphate become virtually equal, varying synchronously on further heating (Figure 13, curve 2). Presumably, an increase in the low-temperature ionic conductivity of the membranes modified with acidic zirconium phosphate is due to the high intrinsic ionic conductivity of finely dispersed $\mathrm{Zr}\left(\mathrm{HPO}_{4}\right)_{2} \cdot n \mathrm{H}_{2} \mathrm{O}$ [40] and to sorption processes occurring at the boundary of the organic and inorganic phases [41].

\section{Conclusions}

We showed that aromatic PADs with moderate molecular weights could be prepared by polyaddition of dinitriles and diamines in acidic ILs. It has been shown that nature of ionic solvent influences on inherent viscosities of resulting polymers. Also we were able to regenerate ionic solvent after polyaddition. Moreover we developed new method of synthesis of such polymers consisting in polycon- densation of 4,4'-oxybis(benzoic acid) diamide and diamines using ER. Molecular weights of synthesized polymers reached $25000 \mathrm{~g} / \mathrm{mol}$, and $10 \%$ weight losses were up to $288^{\circ} \mathrm{C}$, films prepared by casting of PADs solutions in DMF had satisfactory mechanical properties. Resulted PADs were used as precursors for preparation of aromatic PBIs by oxidative dehydrocyclization. It was found that the degree of conversion was not noticeably influenced by the polymer concentration in solution and by its molecular weight, whereas the oxidant content exerted appreciable influence. After doping with phosphoric acid, the ionic conductivity of blend membrane of PBI and PAIR reaches $3 \cdot 10^{-2} \mathrm{~S} / \mathrm{cm}$ at $160^{\circ} \mathrm{C}$. Additional treatment of the doped membrane with acidic zirconium phosphate leads to an increase in the conductivity at low temperatures by almost an order of magnitude $\left(1.0 \cdot 10^{-2} \mathrm{~S} / \mathrm{cm}\right.$ at $\left.23^{\circ} \mathrm{C}\right)$ and to a decrease in the activation energy to $8.5 \pm 0.5 \mathrm{~kJ} / \mathrm{mol}$.

\section{References}

[1] Wang Z-T., Zhang Y-S., Zhao Y-X., Zhu G-M.: Recent progress of polyamidine (in Chinese). Polymer Materials Science and Engineering, 23, 6-9 (2007). DOI: $10.3321 / \mathrm{j}$. issn:1000-7555.2007.05.002

[2] Nikolaeva M. N., Osadchev A. Yu.: Supramolecular structure of the polyamidine-bisphenol system. Russian Journal of Applied Chemistry, 78, 613-616 (2005). DOI: $10.1007 / \mathrm{s} 11167-005-0353-5$

[3] Aleksandrova E. L., Dudkina M. M., Ten'kovtsev A. V.: A mechanism of charge-carrier photogeneration in polyamidine supramolecular structures. Semiconductors, 38, 1284-1290 (2004).

DOI: $10.1134 / 1.1823060$

[4] Dudkina M. M., Tenkovtsev A. V., Komber H., Häussler L., Böhme F.: Competitive influence of carboxylic groups in ionic complex formation of 4-hydroxybenzylidene alkanones with polyamidines. Macromolecules, 37, 8389-8393 (2004).

DOI: $10.1021 / \mathrm{ma} 049466 \mathrm{i}$

[5] Tang R., Ji W., Wang C.: Synthesis and characterization of new poly(ortho ester amidine) copolymers for non-viral gene delivery. Polymer, 52, 921-932 (2011). DOI: $10.1016 /$ j.polymer.2010.12.057

[6] Hwang S. J., Bellocq N. C., Davis M. E.: Effects of structure of $\beta$-cyclodextrin-containing polymers on gene delivery. Bioconjugate Chemistry, 12, 280-290 (2001). DOI: $10.1021 / \mathrm{bc} 0001084$

[7] Böhme F., Klinger C., Komber H., Häußler L., Jehnichen D.: Synthesis and properties of polyamidines. Journal of Polymer Science Part A: Polymer Chemistry, 36, 929-938 (1998).

DOI: $10.1002 /($ SICI)1099-0518(19980430)36:6<929:: AID-POLA8>3.0.CO;2-B 
[8] Toktonov A. V., Mognonov D. M., Mazurevskaya Zh. P., Botoeva S. O.: Synthesis of polyamidines based on aromatic bis(imidoyl) chlorides in solution. Polymer Science Series A, 48, 1-10 (2006).

DOI: $10.1134 /$ S0965545X06010019

[9] Ogata S-I., Kakimoto M-A., Imai Y.: Direct synthesis of new aromatic polyamidines from aromatic diamines and benzoic acids by using poly(trimethylsilylphosphate). Die Makromolekulare Chemie, Rapid Communications, 6, 835-839 (1985).

DOI: $10.1002 /$ marc. 1985.030061208

[10] Sharavanan K., Komber H., Böhme F.: Synthesis and properties of aliphatic polyacetamidines. Macromolecular Chemistry and Physics, 203, 1852-1858 (2002). DOI: 10.1002/1521-3935(200208)203:12<1852::AID-

\section{MACP1852>3.0.CO;2-5}

[11] Lee I-H., Kim H., Choi T-L.: Cu-catalyzed multicomponent polymerization to synthesize a library of poly ( $N$-sulfonylamidines). Journal of the American Chemical Society, 135, 3760-3763 (2013).

DOI: $10.1021 / \mathrm{ja} 312592 \mathrm{e}$

[12] Gol'din G. S., Poddubnyi V. G., Fedorov S. G., Fedotova T. P.: Method for producing polyamidines. SU Patent 248972, USSR (1969).

[13] Fuks R.: $N$-alkylation of nitriles ${ }^{(1)}-$ II. Synthesis polymerization and quaternization of $N$-substituted acrylamidines. A new class of acrylic monomers ${ }^{(16)}$. European Polymer Journal, 9, 835-845 (1973).

DOI: 10.1016/0014-3057(73)90016-5

[14] Brand R. A., Bruma M., Kellman R., Marvel C. S.: Low-molecular-weight polybenzimidazoles from aromatic dinitriles and aromatic diamines. Journal of Polymer Science: Polymer Chemistry Edition, 16, 22752284 (1978).

DOI: $10.1002 /$ pol.1978.170160916

[15] Li Q., Jensen J. O., Savinell R. F., Bjerrum N. J.: High temperature proton exchange membranes based on polybenzimidazoles for fuel cells. Progress in Polymer Science, 34, 449-477 (2009).

DOI: $10.1016 /$ j.progpolymsci.2008.12.003

[16] Barton D., Ollis W. D.: Comprehensive organic chemistry. Vol 2: Nitrogen compounds. Pergamon, Oxford (1979).

[17] Jacques R., Reppelin M., Seigneurin L.: Preparation of aromatic/aliphatic nitriles. U.S. Patent 4436669, USA (1984).

[18] DeCastro C., Sauvage E., Valkenberg M. H., Hölderich W. F.: Immobilised ionic liquids as lewis acid catalysts for the alkylation of aromatic compounds with dodecene. Journal of Catalysis, 196, 86-94 (2000). DOI: $10.1006 /$ jcat.2000.3004

[19] Eaton P. E., Carlson G. R., Lee J. T.: Phosphorus pentoxide-methanesulfonic acid. Convenient alternative to polyphosphoric acid. Journal of Organic Chemistry, 38, 4071-4073 (1973). DOI: $10.1021 / \mathrm{jo} 00987 \mathrm{a} 028$
[20] Farion I. A., Mognonov D. M., Il'Ina O. V., Bal'Zhinov S. A.: Crosslinking benzotriazolylimides and polymeric materials on base of them. Journal of Applied Polymer Science, 126, 1797-1807 (2012).

DOI: $10.1002 /$ app.34475

[21] Oxley P., Partridge M. W., Short W. F.: Amidines. Part VII. Preparation of amidines from cyanides, aluminium chloride, and ammonia or amines. Journal of the Chemical Society, 1947, 1110-1116 (1947).

DOI: $10.1039 /$ JR9470001110

[22] Cooper F. C., Partridge M. W.: N-phenylbenzamidine. Organic Syntheses, 4, 769-533 (1963).

[23] Oxley P., Short W. F.: Amidines. Part I. Preparation of amidines from cyanides. Journal of Chemical Society, 1946, 147-150 (1946). DOI: $10.1039 / J R 9460000147$

[24] Wasserscheid P., Welton T.: Ionic liquids in synthesis. Wiley-VCH, Weinheim (2007).

[25] Boon J. A., Lander S. W., Levisky J. A., Pflug J. L., Skrznecki-Cooke L. M., Wilkes J. S.: Catalysis and reactivity of electrophilic reactions in room temperature chloroaluminate molten salts. in 'Proceedings of the Joint International Symposium on Molten Salts, Pennington, USA' 979-990 (1987).

[26] Boon J. A., Levisky J. A., Pflug J. L., Wilkes J. S.: Friedel-Crafts reactions in ambient-temperature molten salts. Journal of Organic Chemistry, 51, 480-483 (1986). DOI: $10.1021 /$ jo00354a013

[27] Piersma B. J., Merchant M.: Friedel-Crafts alkylation reac-tions in a room temperature molten salt. in 'Proceedings of the $7^{\text {th }}$ International Symposium on Molten Salts, Montreal, Canada' 805-821 (1990).

[28] Newman D. S., Kinstle T. H., Thambo G.: The acylation of coal and model coal compounds in room temperature molten salts. in 'Proceedings of the Joint International Symposium on Molten Salts, Pennington, USA' 991-1001 (1987).

[29] Vygodskii Y. S., Lozinskaya E. I., Shaplov A. S.: Ionic liquids as novel reaction media for the synthesis of condensation polymers. Macromolecular Rapid Communications, 23, 676-680 (2002).

DOI: $10.1002 / 1521-3927(20020801) 23: 12<676:: A I D-$ MARC676>3.0.CO;2-2

[30] Vygodskii Y. S., Lozinskaya E. I., Shaplov A. S., Lyssenko K. A., Antipin M. Y., Urman Y. G.: Implementation of ionic liquids as activating media for polycondensation processes. Polymer, 45, 5031-5045 (2004). DOI: 10.1016/j.polymer.2004.05.025

[31] Lozinskaya E. I., Shaplov A. S., Vygodskii Ya. S.: Direct polycondensation in ionic liquids. European Polymer Journal, 40, 2065-2075 (2004).

DOI: $10.1016 /$ j.eurpolymj.2004.05.010

[32] Mallakpour S., Yosefian H.: Direct polyamidation in molten tetrabutylammonium bromide: Novel and efficient green media. Polymer Bulletin, 60, 191-198 (2008).

DOI: $10.1007 / \mathrm{s} 00289-007-0855-9$ 
[33] Kholkhoev B. C., Burdukovskii V. F., Mognonov D. M.: Polyamidines based on dinitriles and diamines. Russian Journal of Applied Chemistry, 84, 510-511 (2011). DOI: $10.1134 /$ S1070427211030311

[34] Ueda M., Sato M., Mochizuki A.: Poly(benzimidazole) synthesis by direct reaction of diacids and diamines. Macromolecules, 18, 2723-2726 (1985).

DOI: $10.1021 / \mathrm{ma} 00154 \mathrm{a} 060$

[35] Ueda M., Sato M.: Synthesis of aromatic poly(ether ketones). Macromolecules, 20, 2675-2678 (1987). DOI: $10.1021 / \mathrm{ma} 00177 \mathrm{a} 007$

[36] Rusanov A. L., Komarova L. G.: Synthesis of heterochain and heterocyclic condensation polymers in novel reaction media. Polymer Science Series B, 47, 284-303 (2005).

[37] Ponomarev I. I., Rybkin Yu. Yu., Volkova Y. A., Razorenov D. Yu.: Method for producing polybenzimidazoles based on 4,4'-diphenylphthalide-dicarboxylic acid. International Patent WO2008/103066 (2008).
[38] Pretsch E., Buhlmann P., Affolter C.: Structure determination of organic compounds. Springer, Berlin (2000).

[39] Grenda V. J., Jones R. E., Gal G., Sletzinger M.: Novel preparation of benzimidazoles from $\mathrm{N}$-arylamidines. New synthesis of thiabendazole. Journal of Organic Chemistry, 30, 259-262 (1965). DOI: $10.1021 /$ jo01012a061

[40] Casciola M., Bianchi D.: Frequency response of polycrystalline samples of $\alpha-\mathrm{Zr}\left(\mathrm{HPO}_{4}\right)_{2} \cdot \mathrm{H}_{2} \mathrm{O}$ at different relative humidities. Solid State Ionics, 17, 287-293 (1985).

DOI: 10.1016/0167-2738(85)90073-6

[41] Volkov V. V., Mchedlishvili B. V., Roldugin V. I., Ivanchev S. S., Yaroslavtsev A. B.: Membranes and nanotechnologies. Nanotechnologies in Russia, 3, 656-687 (2008).

DOI: $10.1134 / \mathrm{S} 1995078008110025$ 